\title{
VIRTUAL REALITY FOR LOST ARCHITECTURAL HERITAGE VISUALIZATION UTILIZING LIMITED DATA
}

\author{
S. Günay ${ }^{1,2}$ \\ ${ }^{1}$ Oxford Brookes University, Faculty of Technology, Design \& Environment, School of Architecture, Oxford, UK - \\ 17020422@brookes.ac.uk \\ ${ }^{2}$ Canadian University Dubai, Faculty of Architecture \& ID, Dubai, UAE - serkan@cud.ac.ae
}

Commission II

KEY WORDS: VR, Lost Heritage, Data Visualization

\begin{abstract}
:
The process of building digital models of architectural heritage has become increasingly complex and accordingly this enables the potential of utilizing digital techniques as a tool in the context of research. Depending on the objective of the research, there are various tools and outcomes. Ranging from information management projects by using Building Information Modelling (BIM) and Geographical Information Systems (GIS) technologies, to providing Virtual Reality (VR) and Augmented Reality (AR) by using smart technologies for visualization of architectural heritage, there is an increasing demand because of their fast developing technological abilities. Additionally, the digitization processes also becoming less dependent to the information coming from the building and as a result the subject of such research includes buildings that have disappeared without various archival data or other types of historical information. This paper investigates the different visualization techniques and tools for lost architectural heritage examples in postconflict societies with limited available data, focusing on the VR mobile applications and their implementations.
\end{abstract}

\section{INTRODUCTION}

\subsection{Lost Architectural Heritage}

A comprehensive study for an architectural heritage consists of several steps and with each and every step, different kind of data is collected. On site data collection includes the collection of data from the building itself and by interacting with the different stakeholders of the studied architectural heritage, such as current residences, former residences, site managers, etc. On site investigation also includes archival and documentary research from historic resources which also is identified as a valuable data source. Consequently, studies dealing with architectural heritage involves collection of data in different formats in different stages of the operation. Dealing with lost architectural heritage however, the collection of data could be limited due to the fact that the building might have disappeared without a trace and with minimal historical records and documents.

Data has a principal role in defining the strategies concerning architectural heritage visualization especially if the building is lost without adequate historical document or data. It is also a valuable attribute that provide essential discussion points concerning the hidden values of historical buildings and sites. While dealing with this complex and multi-faceted data, it is also critical to provide convenient data management to support the architectural heritage conservation process especially for the heritage visualization.

As mentioned above, architectural heritage itself is an important data provider for the conservation of architectural heritage studies. The researcher could capture various exposed or hidden valuable data by just studying the different historic periods of the architectural heritage that has traces on the building in various formats. The conventional methods of data collection on the site is still valuable even with the rapid technological advancements for the survey phase of architectural heritage studies. However, with the integration of digital technologies, it is now possible to consider the digitization process from data collection to data visualization. Hence, the use of digital technologies allows alternative ways of data digitization as part of the architectural heritage visualization process. The integration of digital technologies in lost architectural heritage visualization on the other hand could define interesting research areas (Günay, 2021). With recently developing technologies in mobile digital devices and tools in architectural heritage visualization, 3D virtual reconstructions can be developed with focuses on outcomes considering the use of these $3 \mathrm{D}$ visuals for research purposes. Virtual reconstructions of architectural heritage, 3DGIS by using web based platforms (Richards-Rissetto et al., 2013), virtual museum applications (Huang \& Han, 2014), virtual reproductions of certain components of architectural heritage (Cruz, 2017; Ramsey, 2017) could be named as some of the advances in using digital technologies in virtual heritage today. The MayaArch3D - University of Nebraska, Temple 22 (Harvard University), Via Appia Antica Project (Virtual Heritage Lab) Safranbolu 3DGIS (Istanbul Technical University) ARCHES Heritage Inventory and Management System (Getty) HBIM for the Basilica di Collemaggio (ENI), SAHRIS (NHRA South Africa) JHBIM (King Abdul Aziz University), HeritageTogether (Bangor University), Byzantium1200 (3D model of Istanbul through Allan Sorrel painting), are some of the several recent projects where the use of information management and integration of 3D visualization are implemented.

Limitations in the collection of historical data require innovative solutions for the visualization process of lost architectural heritage (Bevilacqua et al., 2019). Archival images could be a valuable source of information in addition to cartographic resources (Balletti et al., 2020). Hence, the necessity of gathering visual historical data could enable the virtual reconstruction of lost buildings even though there are limitations in data collection (Günay, 2019). Furthermore, the virtual reconstruction might require assumptions and interpretations since the photographic or cartographic resources could be limited. At this point, it is essential to assess the data source for accuracy and reliability (Knowles, 2018). Discussions around accuracy are related to data resources. A reliable resource such as archival documents or previously done research could enhance the reliability of the outcome (Pietroni \& Ferdani, 2021). This way, the historical 
evidence could be verified by multiple references, and virtual reconstruction of lost architectural heritage could be more authentic.

\subsection{Architectural Heritage Visualization}

Integrating digital technologies in architectural heritage visualization is a developing area of study that finds its earliest examples from early 1980s (Webb \& Brown, 2016) and architectural heritage visualization continue to develop since then. Technologies dealing with $3 \mathrm{D}$ visualization is widely used in several disciplines in various formats. In architecture and particularly in heritage visualization the use of $3 \mathrm{D}$ computer graphics can be found in different formats ranging from collection of data with digital tools or other mobile devices and technologies to 3D printing of an architectural detail. With this research the focus was on using computer generated 3D visualizations and their implementations by using image based modelling and AR/VR technologies in 'Virtual World'.

The term Virtual World from architectural visualization point of view is relevant to the term 'simulation' which is described by the Oxford Dictionary as the production of a computer model of something especially for the purpose of study. Bartle (2004) describes the term as an environment implemented by the computer, which is partially controlled by the individuals (Bartle, 2004). At this point the digitization of data is important and should be done comprehensively.

\subsection{Digitizing the data}

Following the data collection and digitization of data phases, visualization of data in various formats could be achieved by using different digital tools. Digital maps, 2D and 3D drawings and recently popular mobile technologies provide the viewers an understanding of architectural heritage throughout its timeline or with a proposal that sheds light on the possible future interventions. Digital reconstructions of architectural heritage in $3 \mathrm{D}$ platforms offers users visualization options by using mobile devices and tools.

Although 3D virtual reconstructions could be considered as popular, due to the fact that they provide a better understanding of architectural heritage with rendered digital images by using computer technologies, they also bring up challenges of visualizing data interactively in $3 \mathrm{D}$ format. Whether the visualized data is related to the material usage or finishes or it is related to a historic detail, interactive visualization could achieve the data visualization by seeing analytics presented visually with real time changes.

\subsection{The use of VR/AR}

Nowadays VR/AR technologies can be used wider public for different purposes and recently the use of VR/AR technologies for architectural heritage visualization purposes are gaining more and more popularity. Although these technologies and their applications is perceived as something new, the studies and inventions dates back to 1950s. The invention of Morton Heilig (Gladstone et al., 2000) 'Sensorama' is considered the first virtual environment that simulate different experiences including flying a helicopter and riding a bicycle. And later on these technologies commercialized and particularly they are being used for gaming purposes.

The use of VR/AR technologies in heritage visualization also linked with their use in digital museums. They are useful platforms that the public can access via the internet in order to view different objects and display items in virtual environment. Alternatively, digital tools also are being used in museums to digitally perceive the objects or spaces that could require innovative methodologies during the visualization processes.

\section{THE DEVELOPED METHODOLOGY}

\subsection{The Case Studies}

The lost architectural heritage buildings in Izmir (Turkey) and Thessaloniki (Greece) is the subject of this research and 3D models of the selected buildings have been built with reference to the old photos and historic maps for well-known monumental buildings of the city as well as the domestic and non-monumental architectural examples. (Figure 1-2).

Historic photographic documents from digital and city archives provided information to virtually create the $3 \mathrm{D}$ models of these lost architectural heritages. The detail of the model was relevant to the detail of the photographic evidence and accordingly various types of digital models were constructed. Information brought from the photographic documents were mainly related to the proportions, dimensions and identification of certain finish materials of the lost architectural heritage examples of Izmir and Thessaloniki. Due to the fact that majority of these photos were black and white, the relevant information regarding the materials and finishes was also limited.

The virtual reconstructions allowed utilization of these visuals in various platforms for different interpretations of lost heritage examples. As more advanced graphic representations in 3D modelling were developed, advanced 3D interactions became possible to integrate with the created models. Several simulations and mixed media design by superimposing the historical photos with digital model renderings, other types of experimentations were possible. VR experience, as a rapidly developing platform, provided the integration of computer graphics where users can be a part of a computer-generated reality. Additionally, this provided more direct interaction between users and the environment by using mobile devices.

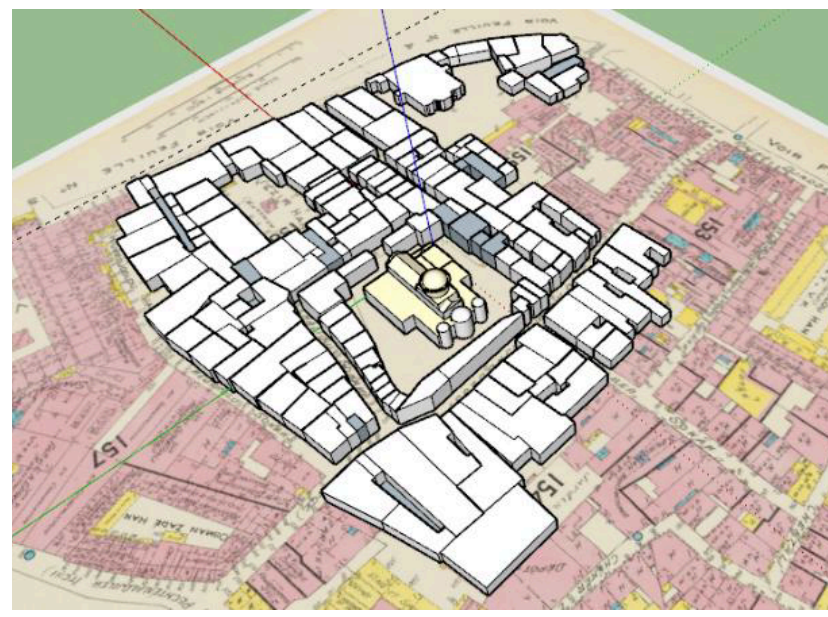

Figure 1. Virtual reconstruction process St. George Church superimposition of historical cartographic resources - Izmir

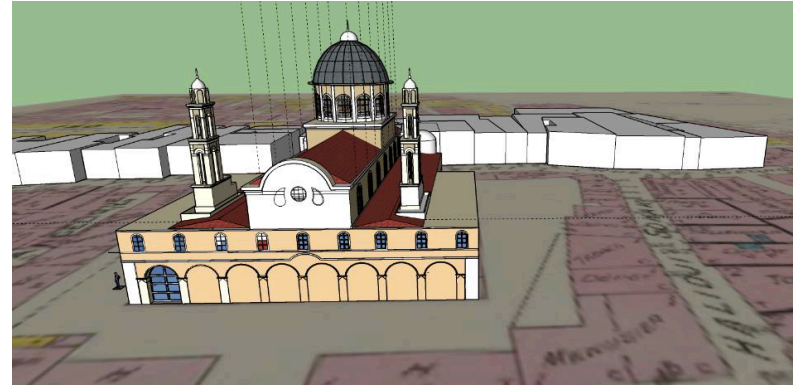

Figure 2. Virtual reconstruction process St. George Church superimposition of historical cartographic resources - Izmir 


\subsection{The Method}

The technological developments and the dynamic information sharing possibilities allow various ways to construct knowledge for architectural heritage visualization. The technologies also have an impact on the creation of knowledge related to the past particularly for the lost heritage examples. Several digital technology solutions were explored while investigating the ways to reintroduce the lost architectural heritage examples for this research.

As key data resources, photographic and cartographic material enabled the creation of the digital architectural models for selected case study lost heritage examples. Virtual reconstructions were possible with the implementation of the Image-Based Modelling (IBM) technique using historical photos. Several archival research allowed the identification of suitable historical images to create the virtual reconstructions of the buildings with their surrounding contexts and relevant building groups. Google Sketch Up enabled the construction of digital models of the selected lost architectural heritage buildings from Izmir and Thessaloniki by matching the historical photos into the 3D (Figure $3-5$ ).

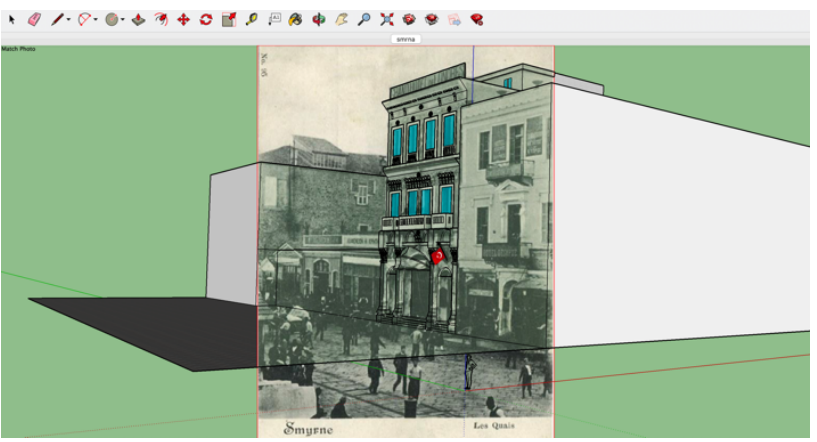

Figure 3. Virtual reconstruction of London Hotel using Image Based Modeling - Izmir

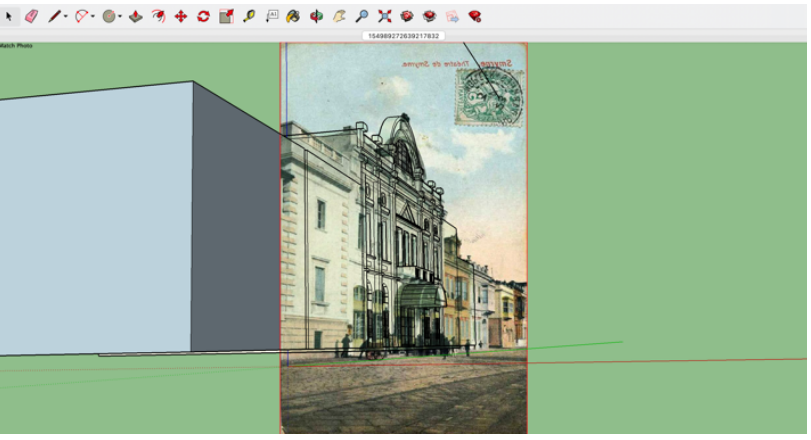

Figure 4. Virtual reconstruction of Smyrna Theatre using Image Based Modeling - Izmir

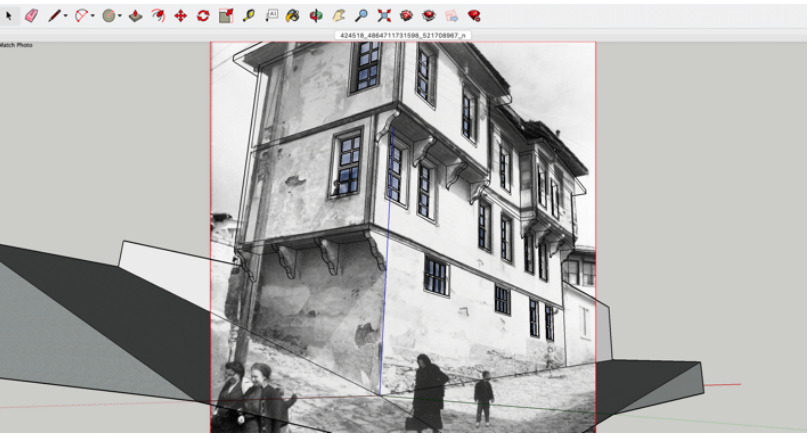

Figure 5. Virtual reconstruction of residential building using Image Based Modeling - Thessaloniki
It was possible to utilize more than one photo within this process. Additionally, historical maps provided information on a plan format which enabled the measurement of the buildings on these maps. The identification of buildings on the studied historical maps was only possible for some of the digital models. The possibility to include more than one photo allowed verification of data collected from these historical photos. For instance, the heights, dimensions, proportions, and other details were checked by comparing different photos. After completing adjustments, taking into consideration the role of depicting the essence of the finishes, materials, colours, street patterns, etc. digital models have been improved to achieve a more realistic and dynamic depiction of these lost architectural heritage examples.

IBM is widely used in architectural heritage representations for documentation or visualization purposes for existing and nonexisting buildings (Kouimtzoglou et al., 2017). The outcome of such works is considered to be better due to the fact that the documentation of an existing structure could be done with high resolution images by following scientific approaches. Dealing with the lost architectural heritage however, IBM could be the only option to visualize a lost heritage in order to generate $3 \mathrm{D}$ digitized architectural model if there are not sufficient architectural documentation or other types of historical documents about the building.

3D architectural models that were generated by IBM were then rendered with further details and for the purpose of creating more realistic virtual experience for the participants to experience the past with more realistic way. After evaluating different software options and various alternatives, renderings have been generated by using Twin Motion on the digital architectural models created with the help of Sketch Up. The panoramic renderings generated from the digital models enabled the creation of VR simulations for a more realistic virtual experience. VR experience was also supported with relevant audio support depicting historic settings and neighbourhoods and also to improve the virtual experience and generate a more realistic audio experience (Figure 6-7).

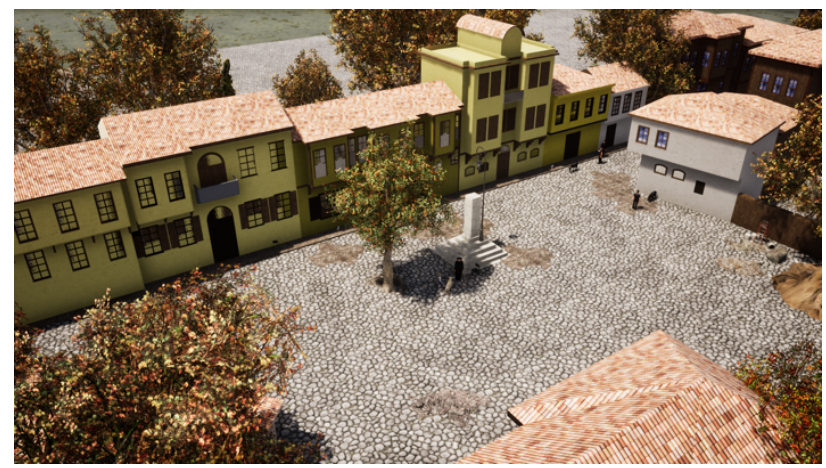

Figure 6. 3D render of Yilanli Mermer District further developed for VR experience- Thessaloniki

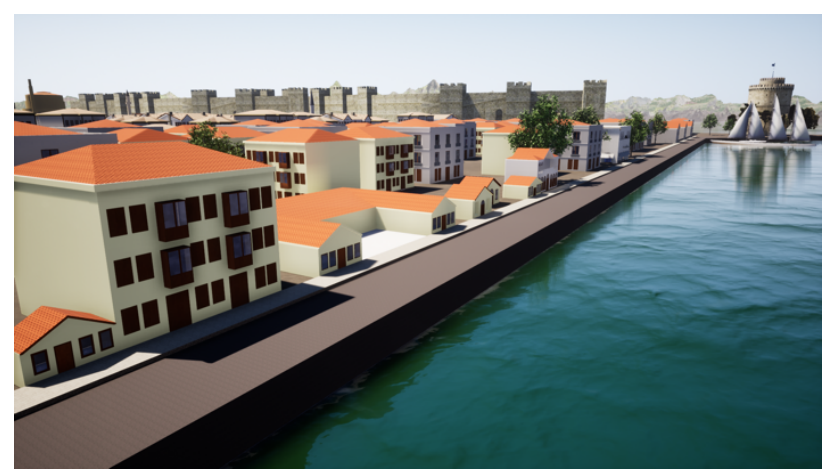

Figure 7. 3D render of Quay of Thessaloniki further developed for VR experience 
Generated 3D models have been visualized with the help of VR/AR mobile applications and through VR goggles and tablet computers as well as mobile devices. These material were a part of fieldwork discussions and during participant observations the above mentioned digital media was shared with the participants and their reaction were explored as part of this research.

\section{THE VIRTUAL ENVIRONMENT}

\subsection{D Visualization}

Producing digitally reconstructed models of lost settlements or buildings provides a virtual platform where digital models of these lost examples could be visualized. The challenging issue regarding the $3 \mathrm{D}$ visualization of lost architectural heritage is the reliability of the historic data. Since the buildings do not exist and in some cases the amount of information gathered from different resources is limited, it is essential to utilize verified data, in other words the data that could be find in more than one historic resources.

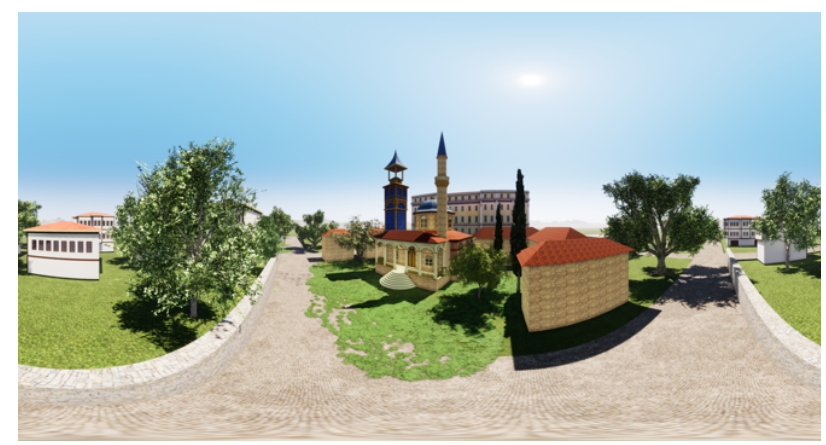

Figure 8. Panoramic image for VR mobile applications of Saatli Camii District, Thessaloniki

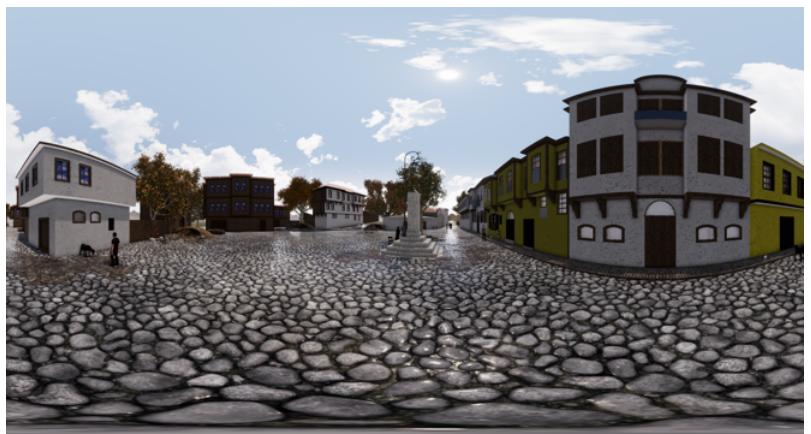

Figure 9. Panoramic image for VR mobile applications of Turkish Quarter, Thessaloniki

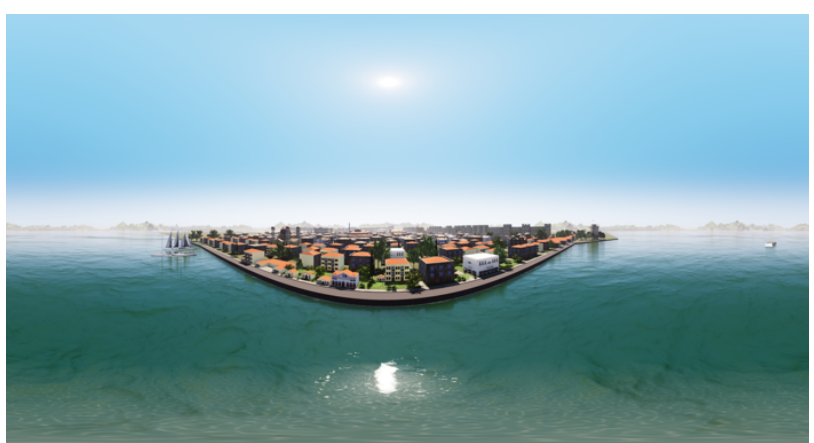

Figure 10. Panoramic image for VR mobile applications of Quay of Thessaloniki
The information displayed with the $3 \mathrm{D}$ reconstructed models should be verified and cross referenced from different sources. Consequently, the outcome is also linked to the building's past or the reason behind its loss. For instance, ongoing or post-conflict situations could affect access to adequate or trustworthy historical data. Furthermore, different than research for a historic building that has partial or complete remains, investigating a lost heritage might end up with limited data sources such as a single photo or even in some cases, just a written description that can give clues about the building's past. Three areas from both cities were the main focus of the VR simulations. Further detailing and adjustments enabled a more realistic experience for the visitors. Although many other models have been built with SketchUp, three areas were selected for VR experience based on their significance (Figure $8-10$ ).

\section{CONCLUSION}

With this research the selected lost architectural heritage buildings in Izmir and Thessaloniki have been virtually reconstructed. The digital models allowed the current residents of these cities virtually experience the disappeared buildings of their cities that belong to societies that have been displaced. The specific cases for lost heritage data collection and visualization allowed the understanding of the previous and current critical issues and challenges. Studies related to lost architectural heritage visualization vary depending on the purpose and depending on the technologies that are implemented. The developing visualization technologies and mobile/wearable digital tools also bring up a flourishing area of visualization techniques for lost architectural heritage examples. The possibility of experiencing the virtually reconstructed architectural or urban heritage examples closer to what it was perceived by its original users is a developing area of research. The review established the link between the current political powers and their role in the selection of lost heritage for heritage interpretations. The impact of ongoing or former conflict on heritage ownership and its link to the perception of heritage by today's residence is a valuable research discussion. Therefore, the need for researching the lost historical buildings with limited data is an area of research that requires attention to overcome the limitations of conflict cases and managing the data for future research. With the development of devices to be integrated into interaction technologies, VR gives the users the feeling of being a part of the digitally generated virtual environment. The users could interact in the virtual environment through 3D interaction input devices and technologies. The concept behind experiencing the past focused on integrating different digital media as well as various outcomes from selected software options.

One of the key contribution of this research is the production of user friendly 3D reconstructions of the lost architectural heritage examples of Izmir and Thessaloniki by using VR and AR technologies. The use of digital technologies allowed the users to experience the previous lives of these cities in digital environment by using different mobile visualization tools. The reason behind the loss of architectural heritage could affect the virtual reconstruction efforts if the building was lost due to a conflict or war. For instance, if the building was built and used by a society or a group that does not live in the area, discussions around heritage ownership might occur. Consequently, new and improving digital technologies allow advanced virtual reconstructions of lost architectural heritage visualizations. The use of digital technologies in lost heritage visualization and its link to heritage and identity relations enable new research areas that this study will further investigate. 


\section{ACKNOWLEDGEMENT}

This paper is an outcome of an ongoing $\mathrm{PhD}$ research titled ‘ Heritage of the 'other': The Future of Lost Architectural Heritage' with the supervision of Dr. Aylin Orbasli and Dr. Henry Abanda in the Faculty of Technology, Design \& Environment of School of Architecture in Oxford Brookes University, Oxford - UK.

\section{REFERENCES}

Balletti, C., Dabrowski, M., Guerra, F., \& Vernier, P., 2020. Digital reconstruction of a lost heritage: the San Geminiano's church in San Marco's Square in Venice. 2020 IMEKO TC-4 International Conference on Metrology for Archaeology and Cultural Heritage Trento, Italy, October 22-24, 2020

Bartle, R. A. 2004. Designing virtual worlds. New Riders Pub.

Bevilacqua, M. G., Caroti, G., Piemonte, A., \& Ulivieri, D., 2019. Reconstruction of Lost Architectural Volumes by Integration of Photogrammetry from Archive Imagery with 3-D Models of the Status Quo. ISPRS Annals of the Photogrammetry, Remote Sensing and Spatial Information Sciences, 42(2/W9), 119-125.

Deggim, S., Kersten, T. P., Lindstaedt, M., Hinrichsen. N., 2017. The return of the Seigesburg - 3D Reconstruction of a Dissapeared and Forgotten Monument. The International Archives of the Photogrammetry, Remote Sensing and Spatial Information Sciences, Volume XLII-2/W3, 2017

Denker, A., 2017. 3D Visualization and Photo-realistic Reconstruction of the Great Temple of Bel. The International Archives of the Photogrammetry, Remote Sensing and Spatial Information Sciences, Volume XLII-2/W3, 2017

Ferrari, F., Medici, M., 2017. Critical Analysis and Digital Reconstructions of Alberti's Architectures by the use of 3D Morphometric Integrated Survey Database. The International Archives of the Photogrammetry, Remote Sensing and Spatial Information Sciences, Volume XLII-2/W3, 2017

Forsyth, M., 2007. Understanding Historic Building Conservation. Oxford: Blackwell Publishing

Forte, M., 2015. Cyberarchaeology: A Post-Virtual Perspective. In Humanities and the Digital: A Visioning Statement, ed. D. T. Goldberg and P. Svensson. Boston: MIT Press.

Gladstone, H. B., Raugi, G. J., Berg, D., Berkley, J., Weghorst, S., \& Ganter, M., 2000. Virtual reality for dermatologic surgery: Virtually a reality in the 21 st century. Journal of the American Academy of Dermatology, 42(1 I), 106-112.

Grussenmeyer, P., Al Khalil, O., 2017. From Metric Image Archives to Point Cloud Reconstruction: Case Study of the Great Mosque of Aleppo in Syria. The International Archives of the Photogrammetry, Remote Sensing and Spatial Information Sciences, Volume XLII-2/W5, 2017

Guidi, G., Russo, M., 2011. Diachronic 3D Reconstruction for Lost Cultural Heritage. International Archives of the Photogrammetry, Remote Sensing and Spatial Information Sciences, Volume XXXVIII-5/W16, 2011
Günay, S., 2019. Geographical information systems as a tool for $3 \mathrm{D}$ visualization of lost architectural heritage. ISPRS Annals of the Photogrammetry, Remote Sensing and Spatial Information Sciences, 4(2/W6), 69-75.

Günay, S., 2021. Impact of integration of digital technologies in lost architectural heritage visualization in post-conflict societies. International Archives of the Photogrammetry, Remote Sensing and Spatial Information Sciences - ISPRS Archives, 46(M-12021), 285-291.

Kersten, T. P., Tschirschwitz, F. T., Deggim, S., 2017. Development of a Virtual Museum Including a 4D Presentation of Building History in Virtual Reality. The International Archives of the Photogrammetry, Remote Sensing and Spatial Information Sciences, Volume XLII-2/W3, 2017

Knowles, J., 2018. Ghastly Vignettes: Pierce the Ploughman's Crede, The Ghost of Shakespeare's Blackfriars, and the Future of the Digital Past. In Meeting the Medieval in a Digital World (pp. 69-91).

Kouimtzoglou, T., Stathopoulou, E. K., Agrafiotis, P., \& Georgopoulos, A., 2017. Image-based 3D reconstruction data as an analysis and documentation tool for architects: The case of Plaka bridge in Greece. International Archives of the Photogrammetry, Remote Sensing and Spatial Information Sciences - ISPRS Archives, 42(2W3), 391-397.

Miranda, A. R., Melon, J. M. V., 2017. Recovering old Stereoscopic Negatives and Producing Digital 3D Models of Former Appearances of Historic Buildings. The International Archives of the Photogrammetry, Remote Sensing and Spatial Information Sciences, Volume XLII-2/W3, 2017

Novitski, B. J., 1998. Rendering Real and Imagined Buildings. Massachusetts: Rackport Publishers

Prieto, J. F., Perea, E. C., Arroyo, L., 2017. Augmented Reality in Architecture: Rebuilding Archeological Heritage. The International Archives of the Photogrammetry, Remote Sensing and Spatial Information Sciences, Volume XLII-2/W3, 2017

Pietroni, E., \& Ferdani, D. 2021. Virtual restoration and virtual reconstruction in cultural heritage: Terminology, methodologies, visual representation techniques and cognitive models. Information (Switzerland), 12(4).

Wahbeb, W., Nebiker, S., 2017. Three Dimensional Reconstruction Workflows for Lost Cultural Heritage Monuments Exploiting Public Domain and Professional Photogrammetric Imagery. ISPRS Annals of the Photogrammetry, Remote Sensing and Spatial Information Sciences, Volume IV-2/W2, 2017

Webb, N., \& Brown, A., 2016. Digital re-analysis of lost architecture and the particular case of Lutyens' Liverpool Metropolitan Cathedral. Frontiers of Architectural Research, 5(2), 265-275. 